\title{
Deformation Mechanism, Microstructure, and Mechanical Properties Evolution of Mg-Gd-Y-Zr Alloy during Cold Torsion
}

\author{
Hongchao Xiao ${ }^{1}$, Zhengjiang Yang ${ }^{2}$, Jie $\mathrm{Li}^{1}$ and Yingchun Wan ${ }^{3, *}$ \\ 1 School of Metallurgy and Environment, Central South University, Changsha 410083, China; \\ hcxiao@csu.edu.cn (H.X.); jielijie@csu.edu.cn (J.L.) \\ 2 School of Materials Science and Engineering, Central South University, Changsha 410083, China; \\ zjyangmse@csu.edu.cn \\ 3 Light Alloy Research Institute, Central South University, Changsha 410083, China \\ * Correspondence: ycwanmse@126.com; Tel.: +86-7318-883-0257; Fax: +86-7318-887-7502
}

check for updates

Citation: Xiao, H.; Yang, Z.; Li, J. Wan, Y. Deformation Mechanism, Microstructure, and Mechanical Properties Evolution of Mg-Gd-Y-Zr Alloy during Cold Torsion. Materials 2021, 14, 2067. https://doi.org/ $10.3390 /$ ma14082067

Academic Editor: Pavel Novák

Received: 3 February 2021

Accepted: 30 March 2021

Published: 20 April 2021

Publisher's Note: MDPI stays neutral with regard to jurisdictional claims in published maps and institutional affiliations.

Copyright: (c) 2021 by the authors. Licensee MDPI, Basel, Switzerland. This article is an open access article distributed under the terms and conditions of the Creative Commons Attribution (CC BY) license (https:// creativecommons.org/licenses/by/ $4.0 /)$.

\begin{abstract}
Mg}-\mathrm{Gd}-\mathrm{Y}-\mathrm{Zr}$ alloy was subjected to torsion of various strain levels at room temperature. Obvious traces of basal slip were observed in the twisted alloy. Dislocations of $<\mathrm{c}+\mathrm{a}>$ were also observed, but there were no signs of significant sliding. Even in the sample whose equivalent strain became $0.294,(10 \overline{1} 0)$ twinning and (1012) twinning were rarely seen. The deformation mode with predominant basal $<a>$ dislocations and subordinate $<c+a>$ dislocations resulted in a modified $Y$ fiber texture with a basal pole slightly dispersed at about $70^{\circ}$ from the twist axis. Mechanical tests revealed that the tensile strength and compressive strengths increased simultaneously after twisting.
\end{abstract}

Keywords: torsion; $\mathrm{Mg}-\mathrm{Gd}-\mathrm{Y}-\mathrm{Zr}$; deformation mechanism; microstructure

\section{Introduction}

Due to high specific strength, high specific stiffness, and high damping capacity, from the perspective of weight reduction, magnesium alloys are becoming the most promising candidates for replacing aluminum alloys and steels in the fields of automobiles, rail transit, aerospace and defense, energy saving, emission control, and vibration absorption. In recent years, significant efforts have been made to overcome the shortcomings of magnesium alloys, such as low strength and low ductility, which limit their application in engineering practice [1-3]. Various reports have revealed that $\mathrm{Mg}$ alloys generally exhibit an excellent strengthening response to plastic deformation due to dynamic recrystallization (DRX)induced grain refinement [4,5], twinning-induced [6], or micro-shear band-induced [7] grain breakage and division. The cold deformation below the DRX temperature has been proven to effectively adjust the microstructure and texture to obtain the desired mechanical properties [8-10]. For example, cold rolling on fine-grained ZK60 alloy introduces a large number of nano-scale deformation bands, which helps to enhance dislocation accumulation and strain hardening [11]. The cold strain during the drawing process of AZ31 alloy results in appreciable twinning and micro-shear bands, which helps to further break the grains into nano-grains [12]. The recrystallized grains obtained in the cold-rolled AZ31 alloy have random orientations and weaken the structure in the early stage of the deformation [13].

Torsional deformation can provide uniform deformation in the longitudinal direction and produce gradient strain in the radial direction. It has been observed that torsion at room temperature can enhance the comprehensive mechanical properties of magnesium alloys. For example, the torsional deformation of AZ31 alloy can help strengthen the alloy by generating twin lamellae, profile dislocations, and weakened texture [14], while the pre-twinned AZ31 alloy shows higher strength [15]. It has also been observed that torsion can improve the tensile strength, compressive strength, and asymmetry of AZ91 alloy [16], and the strength of the alloy increases with the twisting angle. 
Recently, it has frequently been reported that the addition of Gd and $Y$ to magnesium alloys is notably effective in alloy enhancement because of the remarkable aging response caused by precipitation $[17,18]$, and the asymmetry reduction by weakened texture [19]. $\mathrm{Mg}-\mathrm{Gd}-\mathrm{Y}$ alloys have significant advantages in developing wrought magnesium alloys with excellent mechanical properties. However, few studies have focused on the evolution of the microstructure and mechanical properties of $\mathrm{Mg}-\mathrm{Gd}-\mathrm{Y}-\mathrm{Zr}$ alloys during torsional deformation, and the related deformation mechanisms are rarely reported.

The aim of this work was to study the deformation mode, microstructure, and texture evolution of $\mathrm{Mg}-\mathrm{Gd}-\mathrm{Y}-\mathrm{Zr}$ alloy during torsion at room temperature, and to evaluate the effect of the torsional process on the mechanical properties of the alloy.

\section{Experimental Procedures}

The material used in this study was extruded Mg-8Gd-3Y-0.4Zr (wt. \%) alloy, which was obtained by semi-continuous casting, following homogenization and subsequent hot extrusion. The used material had a completely recrystallized structure with a basal texture and an average grain size of $15 \mu \mathrm{m}$, as has been reported in our previous work [20].The received materials were machined into dog-bone specimens with a gauge diameter of 8 $\mathrm{mm}$ and length of $18 \mathrm{~mm}$, according to the American Society for Testing and Materials (ASTM) E8M-09 method, and were denoted as the as extruded (AE). Some AE samples were twisted at room temperature, with the twist axis parallel to the extrusion direction, and a twist rate of $2 \mathrm{rpm}$. The samples were twisted to $8 \%, 28 \%$, and $51 \%$ shear strains and denoted as PT8, PT28, and PT51, respectively. The equivalent strain was estimated according to the following Equation (1):

$$
\varepsilon=\gamma / \sqrt{3}
$$

where $\gamma$ is the shear strain, which can be determined by Equation (2) [21]:

$$
\gamma=2 \pi \mathrm{Nr} / 1
$$

where $\mathrm{N}$ is the number of revolutions, $r$ is the radial position of the sample, and 1 is the gauge length. For PT8, PT28, and PT51, the equivalent strain at the edge of the samples was determined to be $0.046,0.162$, and 0.294 , respectively.

The microstructure characterization was conducted on the FEI Tecnai G2 F20 transmission electron microscope (TEM) (FEI Company, Hillsboro, OR, USA), operated at $200 \mathrm{kV}$, and texture determination was performed on the HELIOS NanoLab 600i Dual Beam Electron Microscope for EBSD ((FEI Company, Hillsboro, OR, USA) observation. Samples for EBSD were prepared by surface electrochemical polishing, and samples for TEM characterization were prepared by twin jet electropolishing. The polishing was conducted in a solution of $97 \%$ alcohol and $3 \%$ nitride acid at $-35^{\circ} \mathrm{C}$. Following the ASTM procedure, the tensile tests were carried out on an Instron 3369 electronic universal machine with a strain rate of $10^{-3} / \mathrm{s}$. All mechanical properties were taken from the arithmetic average of three parallel samples with a gauge diameter of $5 \mathrm{~mm}$ and a gauge length of $25 \mathrm{~mm}$. The hardness tests were conducted on a Vickers hardness tester (Yanrun Company, Shanghai, China) with a load of $4.9 \mathrm{~N}$ and a dwelling time of $15 \mathrm{~s}$. In order to ensure reliability, at least five indentations were made for each test and the average values were recorded.

\section{Results and Discussion}

\subsection{Microstructure}

In order to investigate the texture variation and microstructure evolution, such as grain size and morphology, of the alloy after torsional deformation, EBSD analysis was conducted. Figure 1 presents the EBSD scans on the edge region of the twisted samples with different strains. When observed on the surface perpendicular to the twist axis, the size and shape of the grains did not change significantly, indicating that neither DRX nor grain fragmentation occurred. The inverse pole figures reveal that, compared with the 
starting material, the twisted samples have gradually reduced blue or green grains, and more purple or yellow grains, which indicates that the grains were gradually rotated with the alignment of the c-axis from the radius to the twist axis of the processed bars.
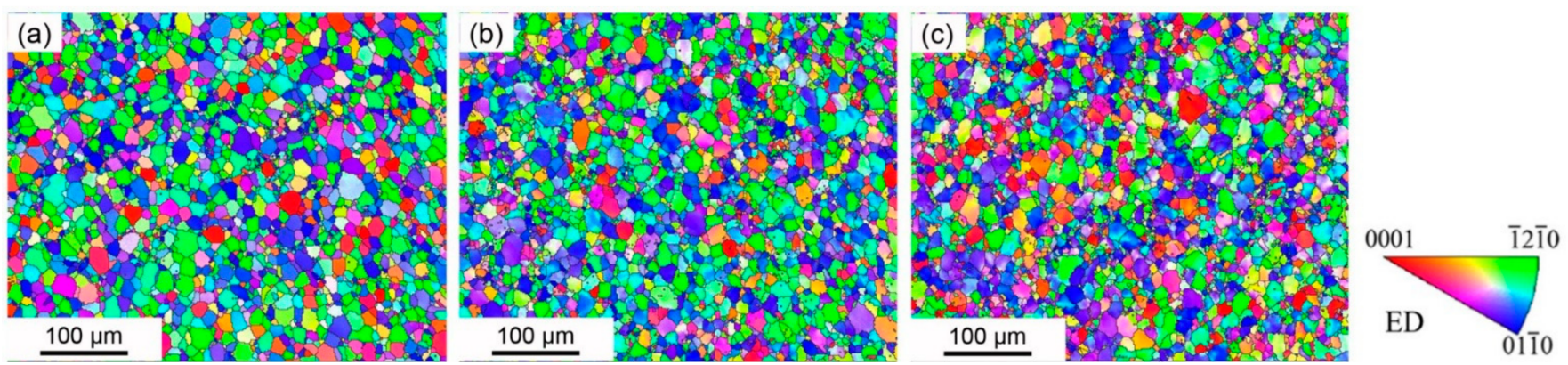

Figure 1. Inverse pole figures of the twisted samples in the edge region (a) PT8, (b) PT28, (c) PT51.

The pole figures corresponding to (0001), (1010), (1011) planes are shown in Figure 2. It can be seen that after the alloy was twisted, the basal pole was rotated from uneven distribution along the radius in the starting material, reaching a concentration slightly deviating from the radius to the twist axis, and the basal pole was located at a position about $20^{\circ}$ from the twist axis in sample PT51. It is worth noting that after the gradual change, the (1011) pole was "reset" on the twist axis. The shear deformation accommodated by <a> dislocations slipping can introduce $Y$ fibers in the Mg alloy with the basal pole located at $60^{\circ}$ away from the twist axis [22]. This texture with a basal pole located at about $70^{\circ}$ away from the twist axis indicates that the activation of a large number of $<a>$ dislocation slips and other deformation modes also have a considerable strain contribution.

(a)

(b)
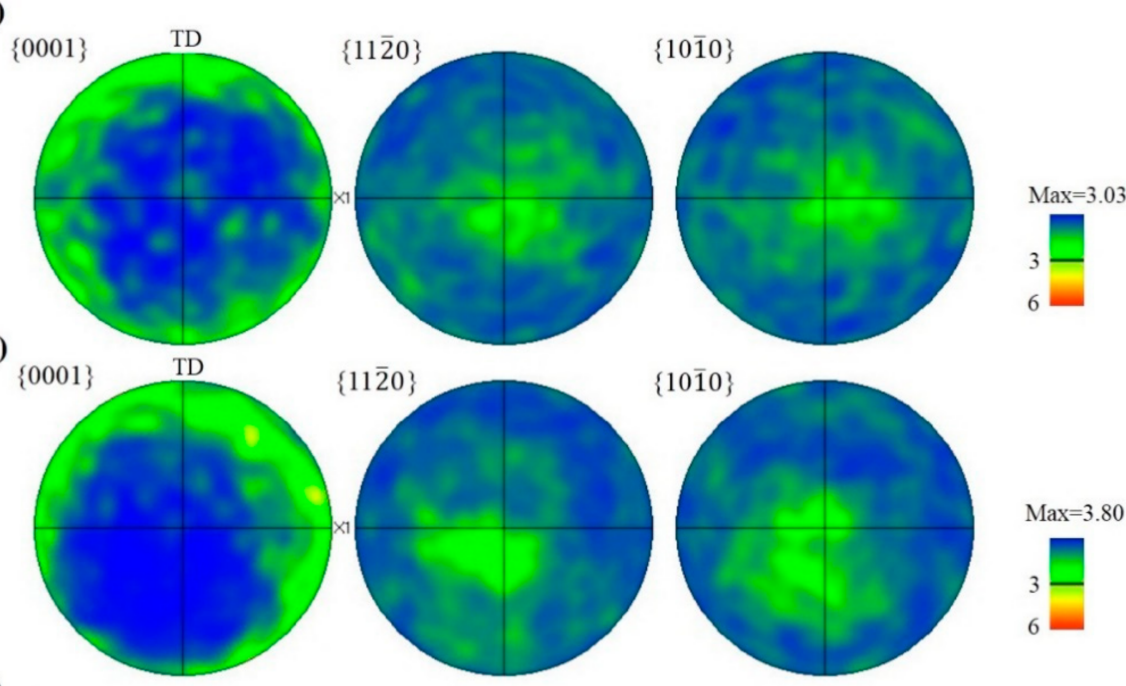

(c)
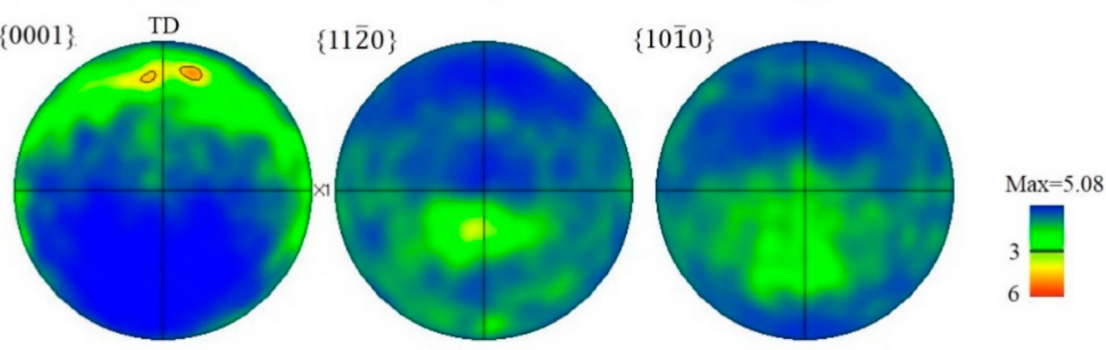

Figure 2. Pole figures corresponding to the (0001), (1010), and (1011) planes of the twisted samples in the edge region (a) PT8, (b) PT28, (c) PT51. 
In the twisted samples, especially in sample PT51, a strong variation in colors inside the grains was observed, indicating the occurrence of a change in orientation. In order to better present this feature, the corresponding local misorientation (LM) distribution is depicted in Figure 3. In all three samples, the LM was found to be higher near the grain boundaries and decreased toward the center of the grains, indicating an increased strain gradient from the center of the grains to the boundaries. This feature reveals that at the beginning of the twisting, the deformation was primarily accommodated in the local area near the grain boundaries until more areas inside the grains were trapped by the strain.
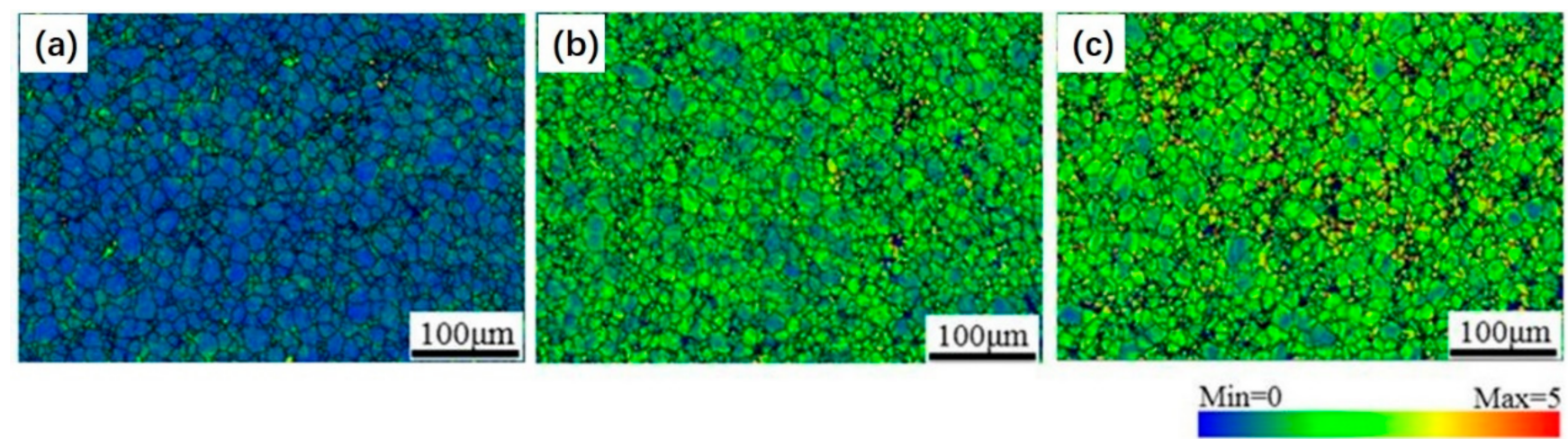

Figure 3. Local misorientation distributions of the twisted samples in the edge region (a) PT8, (b) PT28, (c) PT51.

The boundary angle distribution maps obtained from EBSD are shown in Figure 4, with green for the (1012) twin boundary, pink for the (1011) twin boundary, blue for the low angle boundaries (LABs) of 2-4 degrees, and orange for the LABs of 4-15 degrees. Unlike other deformations, such as forging or rolling conducted at room temperature, in this deformation, the alloys tend to be twinned easily, and very abundant twins were observed in the twisted alloy. Even in the sample whose equivalent strain became 0.294, the fraction of the (1012) twin boundary was less than $3 \%$, and the fraction of the (1011) twinning boundary was less than $1 \%$. Thus, it can be concluded that twinning is not a predominant mode in accommodating the torsional deformation. The fraction of the LABs with misorientation less than 15 degrees exceeded $7 \%$.

In order to further understand the deformation mode and the formation mechanism of the LABs during torsion, TEM characterization was performed. As shown in the TEM bright field (BF) images in Figure 5, a large number of dislocation slipping traces were observed on the (0001) plane, revealing the extensive activation of $<a>$ dislocations. In addition to the basal slipping traces, dislocations or their projections on non-basal planes were also witnessed. As shown in Figure 6a, the BF image obtained with the electron beam parallel to $[10 \overline{1} 0]$ reveals a strong dislocation contrast. In order to determine the Burgers type of dislocations, the dislocation visibility criterion $g \times b \neq 0$ was used, and observations with two different $g$ vectors were conducted, as shown in Figure $6 b, c$. It can be seen that the dislocations are both visible when observed with the $g$ vector of [0001] and the g vector of $[01 \overline{1} 0]$, indicating that the dislocations had both $<\mathrm{c}>$ and $<\mathrm{a}>$ components. As indicated by the red arrows, the most frequently observed dislocation lines are parallel to the (1011) plane, demonstrating that they were $<\mathrm{c}+\mathrm{a}>$ dislocations sliding on the (1011) planes. The observed non-basal slipping traces were far fewer than the basal traces. Thus, it can be concluded that basal $<\mathrm{a}>$ dislocation slipping is the predominant mechanism, and $<\mathrm{c}+\mathrm{a}>$ dislocation slipping on the (1011) plane is subordinate in the simple shear deformation of Mg-Gd-Y-Zr alloy. 
PT8
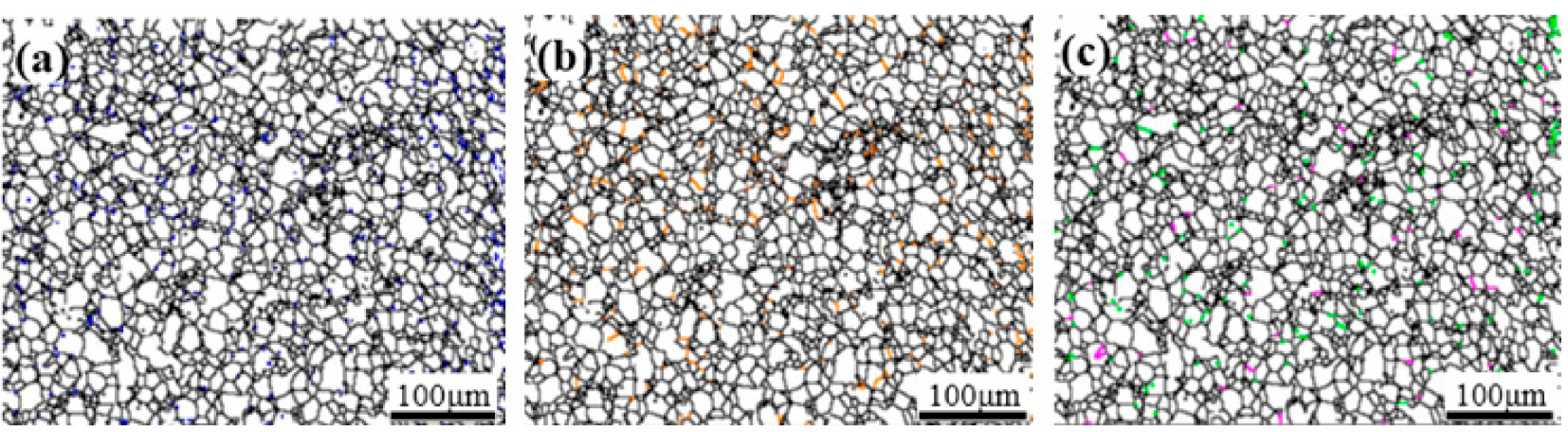

PT28
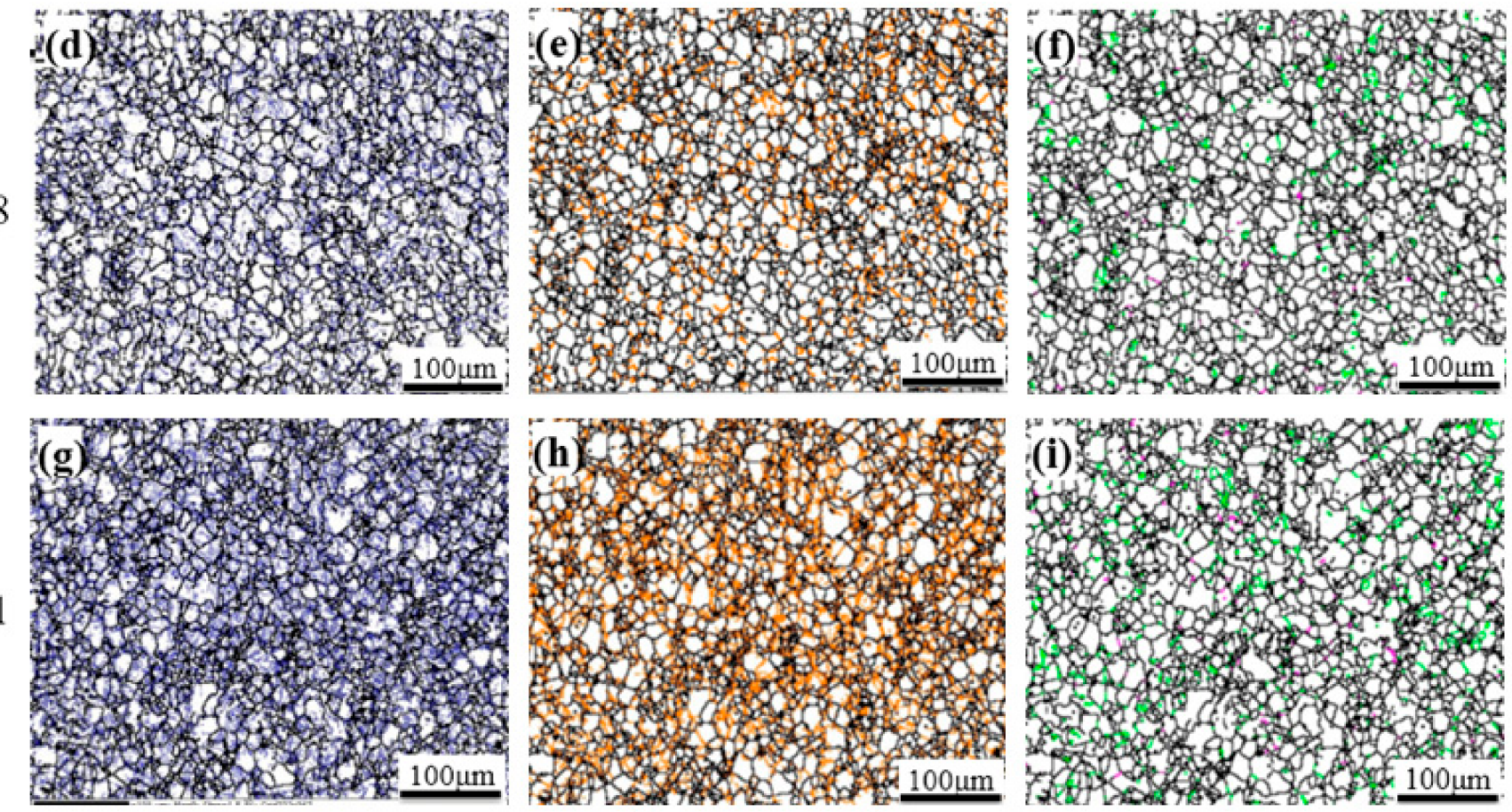

$2 \sim 4^{\circ}$

$$
4 \sim 15^{\circ}
$$
$\{10 \overline{1} 1\}$
High angle boundary

Figure 4. Boundary distributions of the twisted samples in the edge region (a-c) PT8, (d-f) PT28, (g-i) PT51. (a,d,g) for $2 \sim 4^{\circ},(\mathbf{b}, \mathbf{e}, \mathbf{h})$ for $4 \sim 15^{\circ}$ and $(\mathbf{c}, \mathbf{f}, \mathbf{i})$ for tension twin and compression twin.

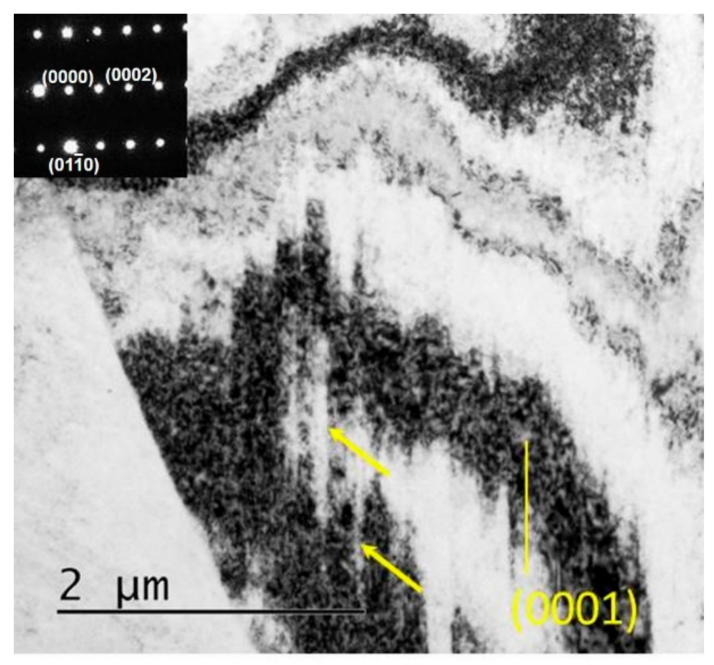

Figure 5. Transmission electron microscope image of sample PT51. 

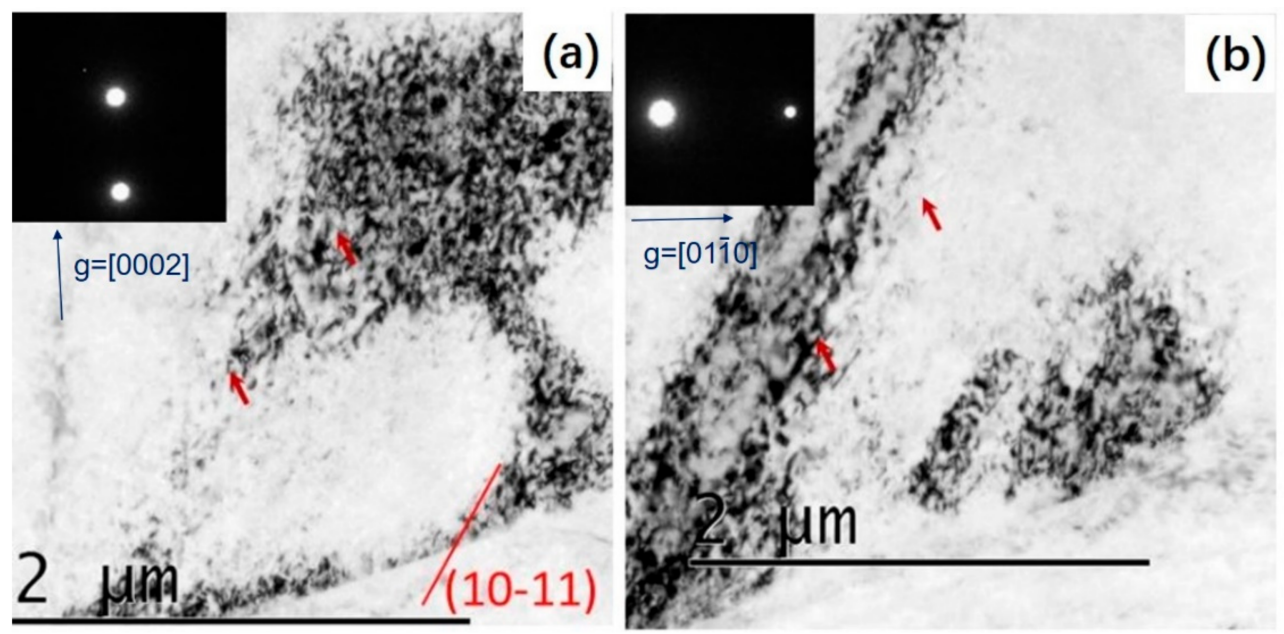

(b)

Figure 6. Transmission electron microscope images of sample PT51. (a) with a g vector of [0002], (b) with a vector of $[01 \overline{1} 0]$.

LABs of $2-15^{\circ}$ have also been observed in the room-temperature forged counterpart, which were characterized to be boundaries between the micro-shear bands and the matrix [7]. The micro-shear bands were generated via piling up dislocations. The <a> dislocations on the basal plane dominated the present distortion and are considered to possess the highest sliding activity. Only after slipping into the prismatic planes were they observed to pile up or rearrange. Therefore, in the twisted alloy, almost no micro-shear bands were observed, as shown in Figure 7. LM is considered to be caused by severe local shear strain induced by the basal slippage near the grain boundaries, but there were no physical boundaries.

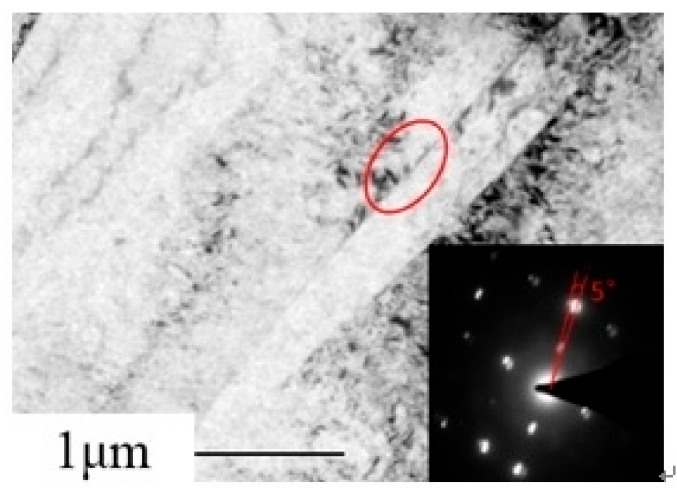

Figure 7. Transmission electron microscope image of sample PT51.

In addition, compared with cold-forged alloys, larger equivalent strains were imposed to the edge regions of the twisted alloy, and the twinning boundaries were much smaller, which indicates that twinning was restricted in simple shear deformation in $\mathrm{Mg}$ alloy.

\subsection{Mechanical Properties}

The mechanical properties of the alloy before and after torsion were investigated by micro-hardness measurements, and tensile and compression tests. Figure 8 shows the Vickers hardness variation along the radius of the alloy. After twisting, due to the gradient structure, the hardness of the sample gradually increased from the center to the edge. The edge region of the sample with the highest strain shows an increase from $76 \mathrm{HV}$ to $93 \mathrm{HV}$. 


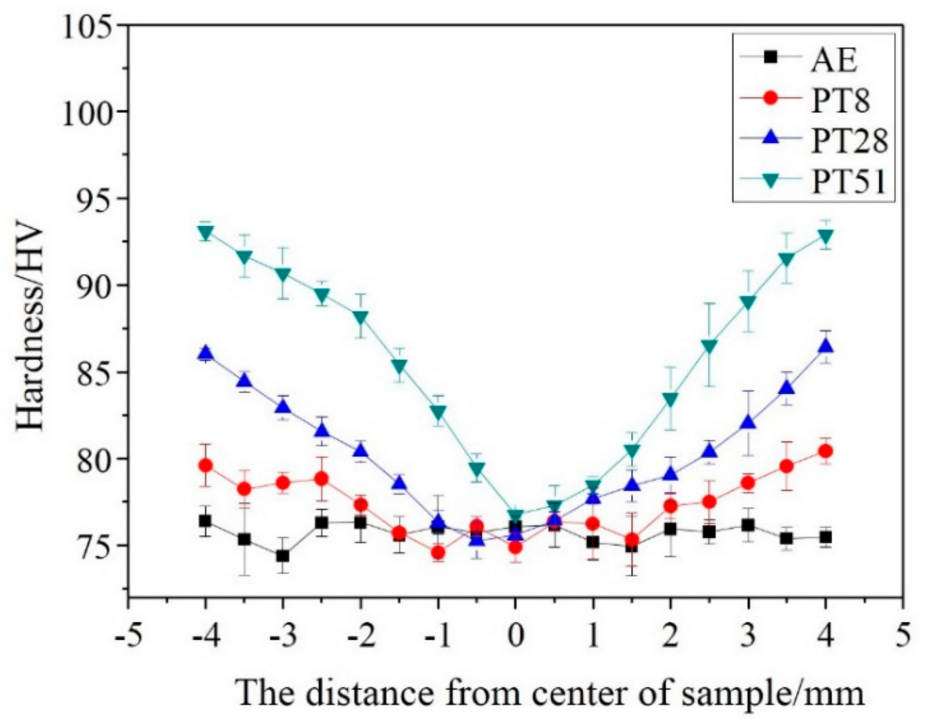

Figure 8. Vickers hardness variation along the radius of the twisted samples.

Figure 9 shows the stress-strain curves of the alloy whose tensile and compression directions were parallel to the twist direction and the corresponding properties are summarized in Table 1. With the increase of strain, the tensile and compressive strength gradually improved. The tensile yield strength increased from $218 \mathrm{MPa}$ to $241 \mathrm{MPa}$, and the compressive strength increased from $239 \mathrm{MPa}$ to $259 \mathrm{MPa}$.
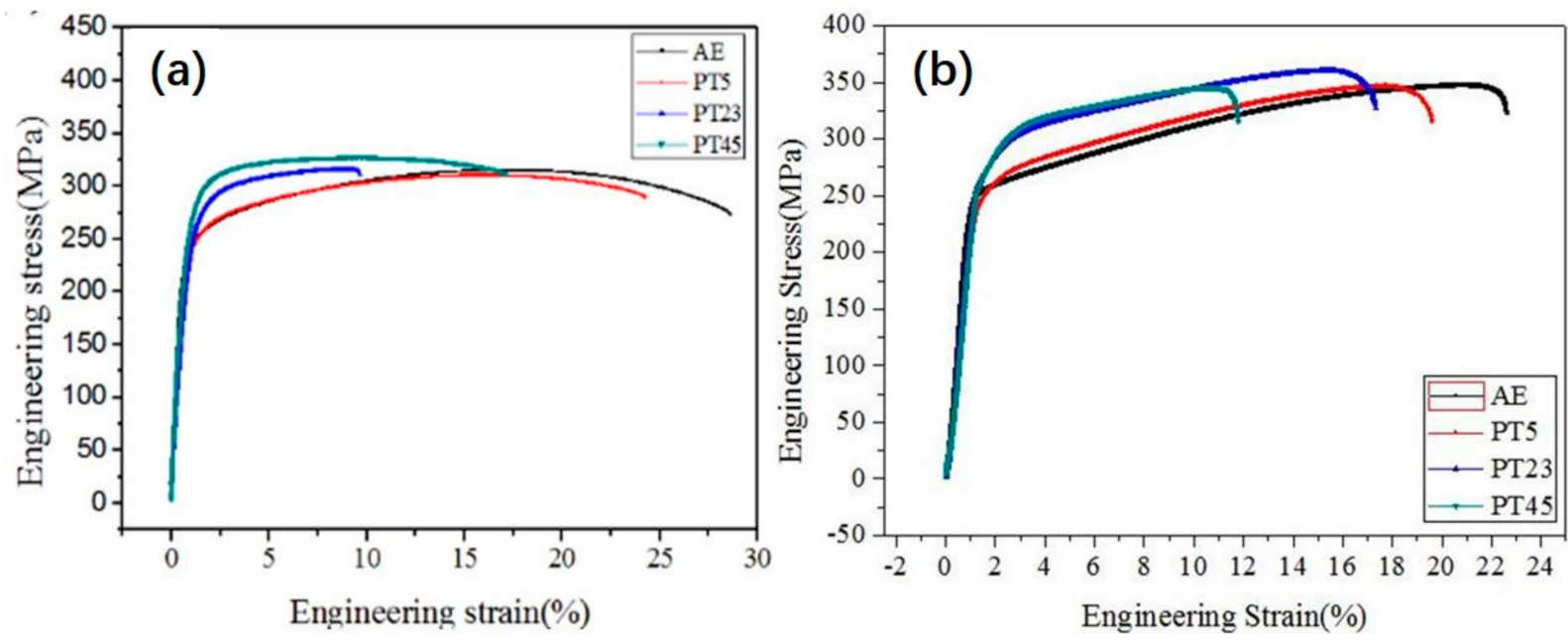

Figure 9. Stress-strain curves of the alloys in (a) tensile and (b) compression tests.

Table 1. Tensile mechanical properties of the samples.

\begin{tabular}{ccccc}
\hline Samples & Test & $\left.\boldsymbol{\sigma}_{\mathbf{y}} \mathbf{( M P a}\right)$ & $\left.\boldsymbol{\sigma}_{\mathbf{u}} \mathbf{( M P a}\right)$ & $\boldsymbol{\Delta}(\mathbf{\%})$ \\
\hline \multirow{2}{*}{ AE } & Ten & 218 & 315 & 28.7 \\
& Comp & 239 & 349 & 21.8 \\
\hline \multirow{2}{*}{ PT8 } & Ten & 221 & 310 & 24.5 \\
& Comp & 241 & 347 & 18.5 \\
\hline \multirow{2}{*}{ PT51 } & Ten & 241 & 327 & 17.3 \\
& Comp & 259 & 346 & 11.0 \\
\hline
\end{tabular}


Compared with the room-temperature forging [7], even a much higher equivalent strain was imposed on the sample, especially in the edge region, and the hardening and strengthening obtained by the room temperature torsion were decreased. This is attributed to the deformation mechanism and the resulting microstructure. The predominant activation of the basal <a> dislocations induced severe local shear and resulted in the strengthening of the dislocation forest in the alloy without producing boundary strengthening from the substructures, such as micro-shear bands and dislocation cells. The deformation-induced strengthening effect for the magnesium alloys depended, to a large extent, on the strain characteristics, not only because of the accumulated level but also because of a distinct difference in microstructures.

\section{Conclusions}

The torsional deformation of $\mathrm{Mg}-\mathrm{Gd}-\mathrm{Y}-\mathrm{Zr}$ alloy was conducted at room temperature, and the related deformation mode, texture evolution, and mechanical properties were investigated. The deformation was predominantly accommodated by the basal $<\mathrm{a}>$ dislocations and subordinately by the $\langle\mathrm{c}+\mathrm{a}>$ dislocations on the (1011) planes, while the twinning was restricted. The deformation resulted in a modified $Y$ fiber texture, the basal pole of which was slightly dispersed and rotated about $70^{\circ}$ away from the twist axis. The distortion caused the tensile and compressive strength of the alloy to increase simultaneously.

Author Contributions: Conceptualization, H.X. and Y.W.; methodology, Z.Y.; validation, J.L.; formal analysis, Y.W.; investigation, Z.Y.; resources, Z.Y.; data curation, Z.Y.; writing-original draft preparation, H.X. and Z.Y.; writing-review and editing, J.L. and Y.W.; supervision, J.L.; project administration, Y.W.; funding acquisition, Y.W. All authors have read and agreed to the published version of the manuscript.

Funding: China Postdoctoral Science Special Foundation (Grant number 2019T120712), China Postdoctoral Science Foundation (Grant number 2018M642999).

Institutional Review Board Statement: Not applicable.

Informed Consent Statement: Not applicable.

Data Availability Statement: Data is contained within the article.

Conflicts of Interest: The authors declare no conflict of interest.

\section{References}

1. Song, D.; Zhou, T.; Tu, J.; Shi, L.; Song, B.; Hu, L.; Yang, M.; Chen, Q.; Lu, L. Improved stretch formability of AZ31 sheet via texture control by introducing a continuous bending channel into equal channel angular rolling. J. Mater. Process. Technol. 2018, 259, 380-386. [CrossRef]

2. Liu, X.; Qiao, X.; Li, Z.; Zheng, M. High strength and excellent ductility of dilute Mg-0.68Al-0.32Ca-0.50Mn (wt\%) extrusion alloy obtained by T6 treatment. Mater. Charact. 2020, 162, 110197. [CrossRef]

3. Li, G.; Zhang, J.; Wu, R.; Liu, S.; Song, B.; Jiao, Y.; Yang, Q.; Hou, L. Improving age hardening response and mechanical properties of a new Mg-RE alloy via simple pre-cold rolling. J. Alloys Compd. 2019, 777, 1375-1385. [CrossRef]

4. Shah, S.; Wu, D.; Wang, W.; Chen, R. Microstructural evolution and mechanical properties of a Mg-Gd-Y alloy processed by impact forging. Mater. Sci. Eng. A 2017, 702, 153-160. [CrossRef]

5. Yu, S.; Liu, C.; Gao, Y.; Jiang, S.; Bao, Z. Dynamic recrystallization mechanism of Mg-8.5Gd-2.5Y-0.4Zr alloy during hot ring rolling. Mater. Charact. 2017, 131, 135-139. [CrossRef]

6. Lu, S.; Wu, D.; Chen, R.; Han, E.-H. Reasonable utilization of $\{10-12\}$ twin for optimizing microstructure and improving mechanical property in a Mg-Gd-Y alloy. Mater. Des. 2020, 191, 108600. [CrossRef]

7. Koike, J.; Kobayashi, T.; Mukai, T.; Watanabe, H.; Suzuki, M.; Maruyama, K.; Higashi, K. The activity of non-basal slip systems and dynamic recovery at room temperature in fine-grained AZ31B magnesium alloys. Acta Mater. 2003, 51, 2055-2065. [CrossRef]

8. Peng, J.; Zhang, Z.; Huang, J.; Guo, P.; Zhou, W.; Wu, Y. The effect of grain size on texture evolution and mechanical properties of an AZ31 magnesium alloy during cold-rolling process. J. Alloys Compd. 2020, 817, 153302. [CrossRef]

9. Li, R.; Xin, R.; Chapuis, A.; Liu, Q.; Fu, G.; Zong, L.; Yu, Y.; Guo, B.; Guo, S. Effect of cold rolling on microstructure and mechanical property of extruded Mg-4Sm alloy during aging. Mater. Charact. 2016, 112, 81-86. [CrossRef]

10. Kim, Y.J.; Kim, S.-H.; Lee, J.U.; Choi, J.O.; Kim, H.S.; Kim, Y.M.; Kim, Y.; Park, S.H. Effects of cold pre-forging on microstructure and tensile properties of extruded AZ80 alloy. Mater. Sci. Eng. A 2017, 708, 405-410. [CrossRef] 
11. Yuan, Y.; Ma, A.; Gou, X.; Jiang, J.; Lu, F.; Song, D.; Zhu, Y. Superior mechanical properties of ZK60 mg alloy processed by equal channel angular pressing and rolling. Mater. Sci. Eng. A 2015, 630, 45-50. [CrossRef]

12. Chen, W.; Zhang, W.; Chao, H.; Zhang, L.; Wang, E. Influence of large cold strain on the microstructural evolution for a magnesium alloy subjected to multi-pass cold drawing. Mater. Sci. Eng. A 2015, 623, 92-96. [CrossRef]

13. Zeng, Z.; Zhu, Y.; Xu, S.; Bian, M.; Davies, C.; Birbilis, N.; Nie, J. Texture evolution during static recrystallization of cold-rolled magnesium alloys. Acta Mater. 2016, 105, 479-494. [CrossRef]

14. Guo, N.; Song, B.; Guo, C.; Xin, R.; Liu, Q. Improving tensile and compressive properties of magnesium alloy rods via a simple pre-torsion deformation. Mater. Des. 2015, 83, 270-275. [CrossRef]

15. Yang, C.; Liu, H.; Yang, B.; Shi, B.; Peng, Y.; Pan, F.; Wu, L. The effect of pre-twinning on the mechanical behavior of free-end torsion for an extruded AZ31 magnesium alloy. Mater. Sci. Eng. A 2019, 743, 391-396. [CrossRef]

16. Zhu, Y.; Liu, F.; Xin, R.; Song, B.; Liu, Q. Improving mechanical properties of an AZ91 alloy by properly combining aging treatment and torsion deformation. Mater. Sci. Eng. A 2020, 779, 139156. [CrossRef]

17. Wang, D.; Fu, P.; Peng, L.; Wang, Y.; Ding, W. Development of high strength sand cast Mg-Gd-Zn alloy by co-precipitation of the prismatic $\beta^{\prime}$ and $\beta 1$ phases. Mater. Character. 2019, 153, 157-168. [CrossRef]

18. Wang, B.; Tang, B.; You, C.; Wan, Y.; Gao, Y.; Chen, Z.; Lu, L.; Liu, C.; Wang, J. Dislocation arrays, precipitate bands and free zones in forged Mg-Gd-Y-Zr alloy. Mater. Sci. Eng. A 2020, 775, 138789. [CrossRef]

19. Stanford, N. Micro-alloying Mg with Y, Ce, Gd and La for texture modification-A comparative study. Mater. Sci. Eng. A 2010, 527, 2669-2677. [CrossRef]

20. Yang, Z.; Liu, C.; Gao, Y.; Guo, X.; Wan, Y. Enhanced Mechanical and Corrosion Performance by Forming Micro Shear Bands in Cold Forged Mg-Gd-Y-Zr Alloy. Materials 2020, 13, 3181. [CrossRef] [PubMed]

21. Shrivastava, C.S.; Jonas, J.J.; Canova, G. Equivalent strain in large deformation torsion testing: Theoretical and practical considerations. J. Mech. Phys. Solids 1982, 30, 75-90. [CrossRef]

22. Beausir, B.; Tóth, L.S.; Neale, K.W. Ideal orientations and persistence characteristics of hexagonal close packed crystals in simple shear. Acta Mater. 2007, 55, 2695-2705. [CrossRef] 